\title{
MOLECULAR AND DYNAMIC SIMULATION OF LOW-TEMPERATURE DEFORMATION OF EXPLICIT ATOM MODEL OF GLASSY POLYMETHYLENE
}

\author{
Mazo Mikhail Abramovich \\ Candidate of Physical and Mathematical Sciences, \\ Senior Researcher, \\ N. N. Semenov Institute of Chemical Physics, RAS \\ mikhail.mazol@gmail.com \\ Kosygina St., 4, 119991 Moscow, Russian Federation
}

\section{Strelnikov Ivan Aleksandrovich}

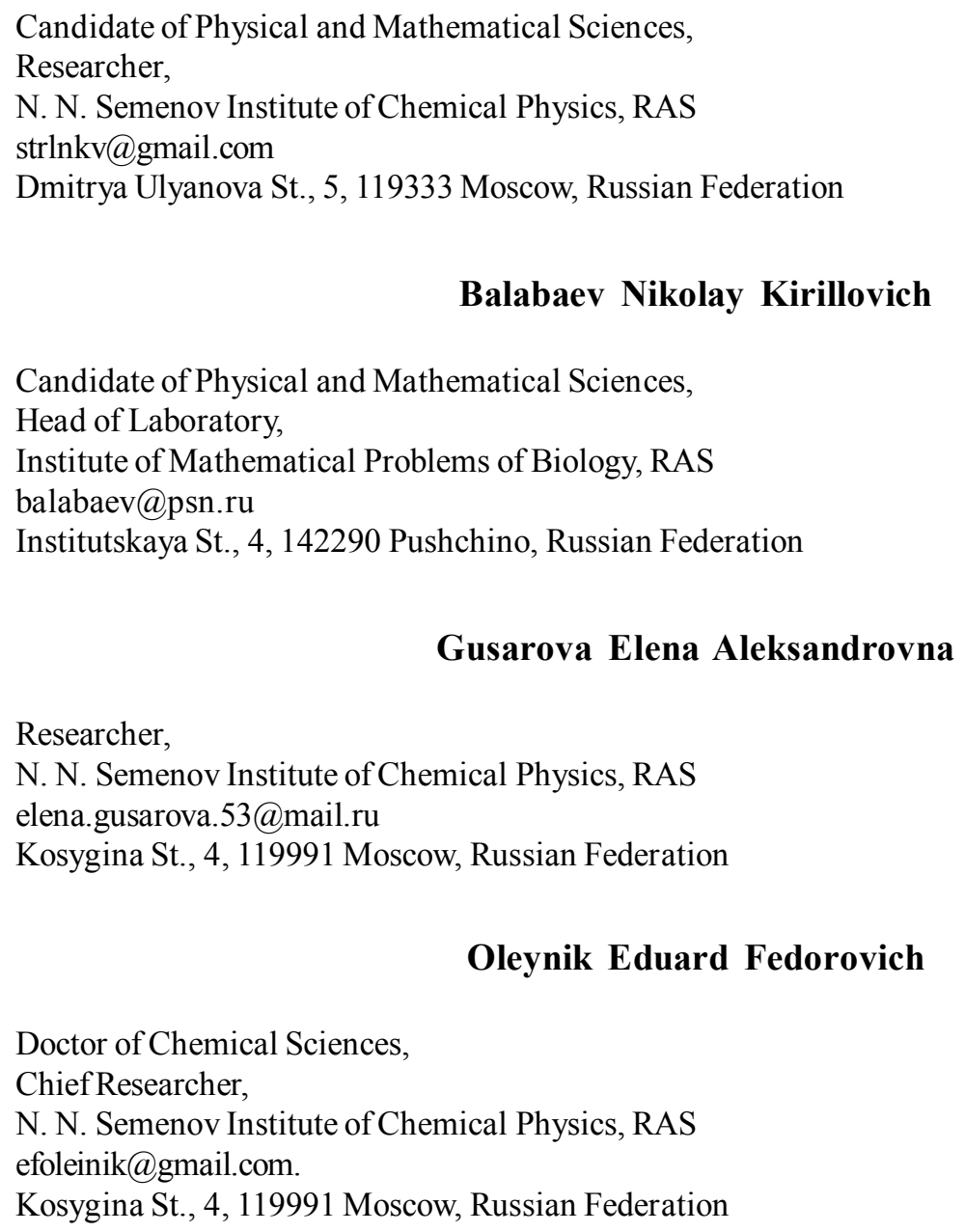

\section{Oleynik Eduard Fedorovich}

Doctor of Chemical Sciences, Chief Researcher, N. N. Semenov Institute of Chemical Physics, RAS efoleinik@gmail.com. Kosygina St., 4, 119991 Moscow, Russian Federation 


\title{
Berlin Aleksandr Aleksandrovich
}

\author{
Doctor of Chemical Sciences, Professor, Academician of RAS, \\ Director of N. N. Semenov Institute of Chemical Physics, RAS \\ berlin@chph.ras.ru \\ Kosygina St., 4, 119991 Moscow, Russian Federation
}

\begin{abstract}
Molecular dynamics simulation of glassy polymethylene (PM) plastic deformation is performed up to $\varepsilon=30 \%$ in uniaxial compression and $60 \%$ in tensile regimes at a temperature of $50 \mathrm{~K}$, which is $\sim 140 \mathrm{~K}$ below $T_{g}$ of the polymer. All atoms of PM chains are represented explicitly. Calculations were performed for two series of samples with different molecular mass distribution of chains. Each sample contains $12288-\mathrm{CH}_{2}-$ monomeric units per computational sell. Contribution from various interactions to potential energy of the system was investigated. Nonaffine displacements of methylene groups and conformational rearrangements in chains during deformation are visualized and analyzed. The transformation of relative fragments of chains up to 16-20 monomer units length are basic structural units, nonconformational displacements of which control plastic process. Relatively large nonaffine displacements are observed even in the range of low strains, which are usually interpreted as Hookean strains. In the range of yield tooth and steady plastic flow, the number of these displacements increases along with their amplitude. Conformational set of PM chains does not show a serious change during deformation. Analysis had shown that the number of conformational rearrangements of trans-gauche type in PM chains during deformation is small and such rearrangements do not play decisive role in the considered range of PM plasticity, even at $\varepsilon>15 \%$, at the stage of the developed plastic flow.
\end{abstract}

Key words: polymethylene, potential energy, plastic deformation, molecular mass, fragments of chains, low strains.

\section{Introduction}

The study of the plastic deformation of glassy solids via computer simulation methods has noticeably developed over the past few years $[2$; $3 ; 12 ; 21 ; 28]$. The same is true for the study of deformation of glassy polymers $[6 ; 8 ; 10 ; 25 ; 37$; $43 ; 47]$. However, the role of chain motions in the inelastic deformation of these polymers remains unclear. Early ideas about the inelastic deformation of glassy polymers are based on the pattern that plastic mass transfer is related to motions of chain segments whose displacements under an external force are responsible for changes in the sizes and shapes of macromolecular coils and samples. In addition, it was assumed that the conformational unfolding of chains [27] or the formation of kinks in the chain backbone [3] play a marked role in the plasticity of glassy polymer systems. However, as was shown experimentally, changes in conformational composition with an increase in deformation occur only at very large strains in the strain hardening region [37]. At low and modest strains $(\leq 40 \%)$, changes in conformational composition are seen in neither vibrational [36; 46] nor NMR spectra [49]. Numerical simulations showed also that, although deformation is responsible for noticeable conformational mobility, the conformational composition of samples at moderate strains vary insignificantly $[5 ; 8 ; 17 ; 24$; $26 ; 33 ; 47 ; 48]$ and the conformational composition change at very high strains solely in the strain hardening range $[17 ; 24 ; 33]$.

Modern models of the plasticity of glassy solids and polymers consider new mechanism: plastic processes in these systems consist of either nucleation of localized shear transformations with increases in their concentration during loading and subsequent relaxation $[4 ; 6 ; 14 ; 33]$ or formation of localized zones of shear transformations [13; $22 ; 44]$. An increment of plastic strain arises in glassy structures owing to the appearance of nonaffine atomic displacements in shear transformations or zones [22].

In the present study, the molecular dynamics simulation of the uniaxial compression of the 
amorphous polymer at a temperature of $50 \mathrm{~K}$ is performed of all atom model of glassy polymethylene (PM). Nonaffine displacements of skeletal atoms of the polymers at different strain levels are accentuated and visualized, and the forms of displacements of atoms of macromolecules in the glassy state of the PM material during its macroscopic plastic deformation are analyzed. In analysis of atomic displacements that occur during deformation of the material, an attempt is made to reveal the participation of conformational rearrangements in the process and to quantify their contribution.

\section{Preparation of Samples for Simulation}

Amorphous PM samples were prepared in several steps. First, 3072 "butadiene" $\mathrm{C}_{4} \mathrm{H}_{8}$ molecules in the trans configuration that contain only two hydrogen atoms per end groups were uniformly distributed in a computational cell with periodic boundary conditions. The density of the system was extremely low $\left(0.07 \mathrm{~g} / \mathrm{cm}^{3}\right)$. This configuration was chosen as the initial one for molecular dynamics calculations. In cell, a temperature of $800 \mathrm{~K}$ was maintained for $182 \mathrm{ps}$, whereas the volume was continuously decreased via hydrostatic compression of the computational cell from a density of $0.07 \mathrm{~g} / \mathrm{cm}^{3}$ to $0.8 \mathrm{~g} / \mathrm{cm}^{3}$. Thus, with the use of independent sequences of pseudorandom numbers for a thermostat, 32 various samples of liquid "butadiene" were obtained.

At the next step, "butadiene" was polymerized at a constant volume. At each step of molecular dynamics calculation during this process, end carbon atoms of molecules (for both initial "butadienes" and synthesized polymers) that were at a distance shorter than $3.5 \mathrm{E}$ and did not belong to the same molecule were bound via a harmonic potential. This procedure produced no branching, because once-bound atoms were no longer considered end atoms. When polymerization was completed, new lists of valence bonds and valence and torsional angles were composed for the synthesized polymer systems.

Two series of calculations were conducted. In series C1 (32 samples), polymerization was performed with simultaneous cooling to $300 \mathrm{~K}$ at a rate of $5 \mathrm{~K} / \mathrm{ps}$ followed by keeping of the samples at this temperature and a constant volume for $60 \mathrm{ps}$. Then, the polymer samples were kept at a thermostat temperature of $300 \mathrm{~K}$ and an external pressure of $1 \mathrm{~atm}$ for $1 \mathrm{~ns}$. During this time, the internal temperatures, pressures, and components of the potential energy for the samples attained constant values.

In the second calculation series $\mathrm{C} 2$ (8 samples), polymerization was performed for $100 \mathrm{ps}$ at $800 \mathrm{~K}$ followed by relaxation of the formed polymer system for 86 ps with a new list of valence bonds. Afterward, these samples were cooled at a constant volume to $300 \mathrm{~K}$ at a rate of $5 \mathrm{~K} / \mathrm{ps}$ and were kept at this temperature and a constant volume for $90 \mathrm{ps}$. Then, the samples were relaxed at a temperature of $300 \mathrm{~K}$ and a pressure of $1 \mathrm{~atm}$ for $86 \mathrm{ps}$. After all relaxation procedures, the densities of the samples attained equilibrium values of $0.804 \pm 0.002 \mathrm{~g} / \mathrm{cm}^{3}$ and $0.808 \pm 0.001 \mathrm{~g} / \mathrm{cm}^{3}$ for $\mathrm{C} 1$ and $\mathrm{C} 2$, respectively. These values are somewhat lower than the experimental values $\left(0.853 \mathrm{~g} / \mathrm{cm}^{3}\right)$ in the amorphous phase of semicrystalline PE [6].

Because the polymerization conditions in both series were different, the length distributions of chains in them were likewise somewhat different. For samples of series $\mathrm{C} 1$, the average degree of polymerization was $211 \pm 16$ $\left(M_{n}=2955 \pm 220, M_{w}=6011 \pm 790\right.$, and a polydispersity index of $2.034 \pm 0.22$ ). For series $\mathrm{C} 2$, the average degree of polymerization was $352 \pm 36\left(M_{n}=4923 \pm 500, M_{w}=9548 \pm 1270\right.$, and a polydispersity index of $1.955 \pm 0.31$ ). Longer chains (up to 1800 methylene groups) were formed in series $\mathrm{C} 2$, but noticeable amounts of short oligomers composed of 4-10 methylene groups were present in both series (Fig. 1).

At the third step, all samples were cooled at a constant rate from $300 \mathrm{~K}$ to $50 \mathrm{~K}$ for $250 \mathrm{ps}$ at a constant pressure of 1 atm followed by relaxation of this system at this temperature for 400 ps. Glass-transition temperatures $T_{g}$ were estimated from the temperature dependence of density (Fig. 2). The values of $T_{g}$ obtained for both series were slightly different owing to different degrees of polymerization: $171 \pm 6 \mathrm{~K}$ for series $\mathrm{C} 1$ and $180 \pm 10 \mathrm{~K}$ for series $\mathrm{C} 2$. These estimates are close to the experimental value of $190 \mathrm{~K}$ [6]. Slightly underestimated glass-transition temperatures may be explained by a high cooling rate of the samples. For $\mathrm{C} 1$ and $\mathrm{C} 2$ samples, densities at $50 \mathrm{~K}$ were found to be close to $0.867 \mathrm{~g} / \mathrm{cm}^{3}$, respectively. 


\section{ТЕХНИКО-ТЕХНОЛОГИЧЕСКИЕ ИННОВАЦИИ}

Intra and inter molecular interactions were calculated with the use of the AMBER99 force field [51]. The parameters of potentials of atomatom interactions used for the simulation are presented below (Table 1), where $\mathrm{C}$ designates carbon atoms and $\mathrm{H}$ designates hydrogen atoms. For numerical integration of the equations of motion, the Verlet velocity algorithm was used [1]. The integration step was $0.5 \mathrm{fs}$. Temperature in the system was maintained with a collisional thermostat [30], pressure was set and maintained with the Berendsen barostat [11].

\section{Results and Discussions}

\subsection{Stress-Strain Diagrams}

Plots show the obtained stress-strain $\sigma-\varepsilon$ diagrams at two loading rates. The patterns of the diagrams are typical for glassy polymers: namely, a linear dependence at low strains $(\varepsilon<5 \%)$ followed by a yield peak $(5 \%<\varepsilon<$ $12 \%)$ with a yield tooth strain of $\varepsilon_{y} \sim 12-14 \%$. At $\varepsilon>20 \%$, the steady plastic flow state sets in. For $\mathrm{C} 1$ and $\mathrm{C} 2$ samples, the diagrams practically coincide (Fig. 3).

Young's modulus is $3.8 \mathrm{GPa}$ and yield stress in the tooth $\sigma_{y}$ is $220 \mathrm{MPa}$ in stretching. Compressive modulus $E$ and yield stress in the tooth $\sigma_{y}$ depend on the strain rate: at $50 \mathrm{~K}$ and a rate of $\dot{\varepsilon}=10^{-3} \mathrm{ps}^{-1}$ (Fig. 2, $b$, curve 3), $E=4.41 \mathrm{GPa}$ and $\sigma_{y}=400 \mathrm{MPa}$, while at $\dot{\varepsilon}=10^{-4} \mathrm{ps}^{-1}, E=3.83 \mathrm{GPa}$ and $\sigma=330 \mathrm{MPa}$. The calculated values of $E$ are close to the experimental values for glassy polymers. However, the values of $\sigma_{y}$ are about 45 times higher than the experimental data [39]. This fact is usually explained by very high loading

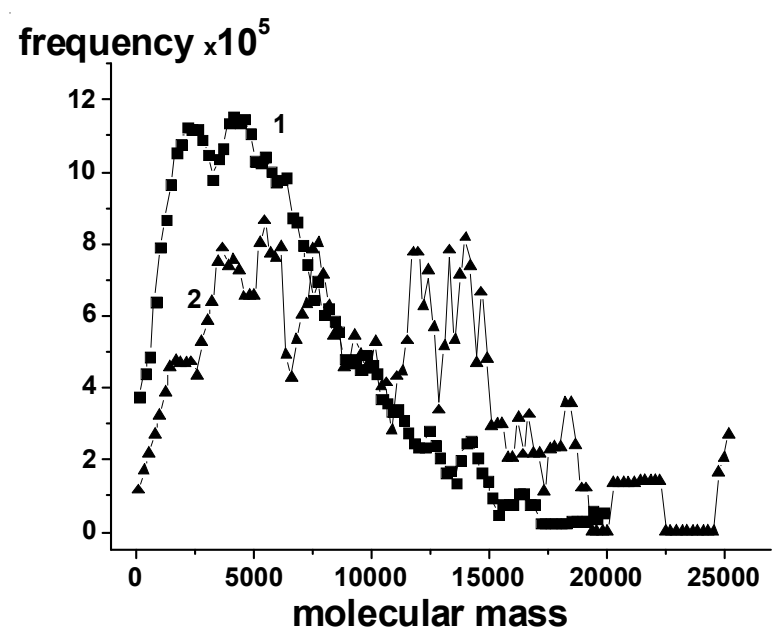

Fig. 1. Molecular mass distribution (-ח-C1 samples; $-\mathbf{\Delta}-\mathrm{C} 2$ samples), the step is $224 \mathrm{amu}$

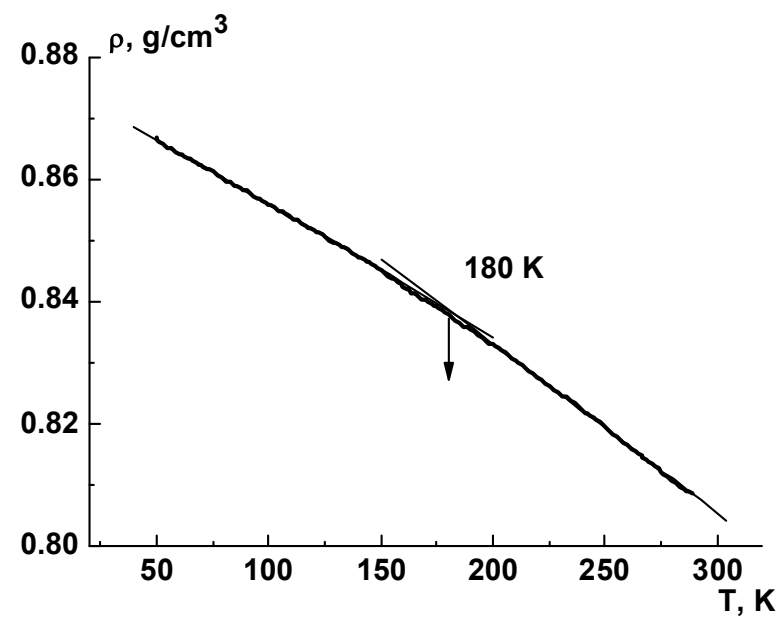

Fig. 2. Variation in the density of $\mathrm{C} 2$ samples with temperature. The $T_{g}$ value is marked by an arrow 


\section{ТЕХНИКО-ТЕХНОЛОГИЧЕСКИЕ ИННОВАЦИИ}

rates during simulation, but it may be caused also by a high internal-stress level in the polymer system prior to its deformation [6;48]. The Poisson ratio in all cases was $0.40 \pm 0.03$.

Fig. 4 presents the curves of the density of PM glass in the course of its deformation in compression and stretching. It might be expected that a specimen in stretching is substantially expanded, but the observed density decrease turned out to be unexpectedly large $(\approx 8 \%$ at $\left.\varepsilon_{t}=30 \%\right)$. In compression, the calculated PM density varies insignificantly (within $1 \%$ ), which we observed previously in compression of oligomers [10]. So noticeable differences between the glassy PM density changes have a considerable effect on the contributions of interactions of various types to the increase in the internal energy of PM glass in deformation.

\subsection{Internal Energy}

Fig. 5 illustrates the internal energy changes $\Delta U_{\text {in }}$ in compressive and tensile deformation of specimens and the contributions of interatomic interactions of various types to them. As it was expected [6] and according to the experimental data [45], the total internal energy (curves 1) of glassy PM increases both in stretching and in

Table 1

Potential parameters of atom-atom interactions are used for the simulation.

$\mathrm{C}$ - carbon atoms, $\mathrm{H}$ - hydrogen

\begin{tabular}{|c|c|}
\hline \multicolumn{2}{|c|}{ Valence bond potential: $\mathrm{U}(\mathrm{L})=\mathrm{K}_{\mathrm{L}} \cdot\left(\mathrm{L}-\mathrm{L}_{0}\right)^{2}$} \\
\hline $\mathrm{C}-\mathrm{C}: \mathrm{L}_{0}=1.526 \mathrm{E}$ & $\mathrm{K}_{\mathrm{L}}=310 \mathrm{kcal} / \mathrm{mol} / \mathrm{E}^{2}$ \\
\hline $\mathrm{C}-\mathrm{H}: \mathrm{L}_{0}=1.090 \mathrm{E}$ & $\mathrm{K}_{\mathrm{L}}=340 \mathrm{kcal} / \mathrm{mol} / \mathrm{E}^{2}$ \\
\hline \multicolumn{2}{|c|}{ Valence angle potential: $\mathrm{U}(\theta)=\mathrm{K}_{\mathrm{L}} \cdot\left(\theta-\theta_{0}\right)^{2}$} \\
\hline C-C-C: $\theta_{0}=109.5^{\circ}$ & $\mathrm{K}_{\theta}=40 \mathrm{kcal} / \mathrm{mol} / \mathrm{rad}^{2}$ \\
\hline $\mathrm{C}-\mathrm{C}-\mathrm{H}: \theta_{0}=109.5^{\circ}$ & $\mathrm{K}_{\theta}=50 \mathrm{kcal} / \mathrm{mol} / \mathrm{rad}^{2}$ \\
\hline $\mathrm{H}-\mathrm{C}-\mathrm{H}: \theta_{0}=109.5^{\circ}$ & $\mathrm{K}_{\theta}=35 \mathrm{kcal} / \mathrm{mol} / \mathrm{rad}^{2}$ \\
\hline \multicolumn{2}{|c|}{ Potential energy of rotation angles: $\mathrm{U}(\varphi)=\mathrm{K}_{\varphi} \cdot(1+\cos (3 \varphi))$} \\
\hline $\mathrm{X}-\mathrm{C}-\mathrm{C}-\mathrm{X}$ & $\mathrm{K}_{\varphi}=0.156 \mathrm{kcal} / \mathrm{mol}$ \\
\hline$(\mathrm{X}=\mathrm{C}$ или $\mathrm{X}=\mathrm{H})$ & \\
\hline \multicolumn{2}{|c|}{$\begin{array}{c}\text { Van-der-Waals interactions between atoms of different molecules or } \\
\text { atoms separated by more than two atoms in the same chain: } \\
U_{\mathrm{VW}}(\mathrm{r})=\mathrm{U}_{\mathrm{LJ}}(\mathrm{r})-\mathrm{U}_{\mathrm{LJ}}\left(\mathrm{R}_{\text {off }}\right) ; r<\mathrm{R}_{\text {off }}, R_{\text {off }}=10.5 \mathrm{E} \\
U_{\mathrm{LJ}}(\mathrm{r})=\varepsilon \cdot\left[\left(\mathrm{R}_{\min } / \mathrm{r}\right)^{12}-2 \cdot\left(\mathrm{R}_{\min } / r\right)^{6}\right]\end{array}$} \\
\hline$\varepsilon_{\mathrm{CC}}=0.1094 \mathrm{kcal} / \mathrm{mol}$ & $\mathrm{R}_{\min , \mathrm{CC}}=3.816 \mathrm{E}$ \\
\hline$\varepsilon_{\mathrm{HH}}=0.0157 \mathrm{kcal} / \mathrm{mol}$ & $\mathrm{R}_{\min , \mathrm{HH}}=2.974 \mathrm{E}$ \\
\hline$\varepsilon_{\mathrm{CH}}=\left(\varepsilon_{\mathrm{CC}} \cdot \varepsilon_{\mathrm{HH}}\right)^{0.5}$ & $\mathrm{R}_{\min , \mathrm{CH}}=0.5 \cdot\left(\mathrm{R}_{\min , \mathrm{CC}}+\mathrm{R}_{\min , \mathrm{HH}}\right)$ \\
\hline
\end{tabular}

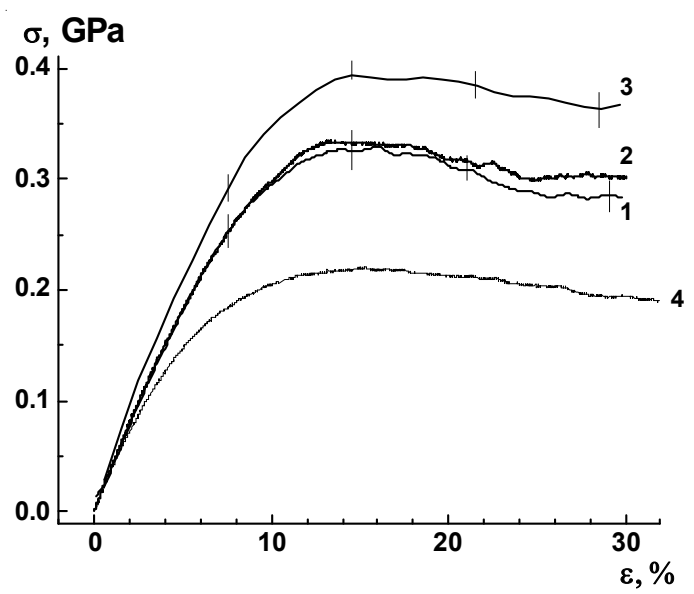

Fig. 3. Diagrams $\sigma-\varepsilon$ obtained via simulation:

1-3-compression, 4 -tension.

$(1,4) \mathrm{C} 1$ samples at $\dot{\varepsilon}=10^{-4} \mathrm{ps}^{-1}$ and $(2,3) \mathrm{C} 2$ samples at $\dot{\varepsilon}=(2) 10^{-4}$ and (3) $10^{-3} \mathrm{ps}^{-1}$, respectively; $T_{\text {def }}=50 \mathrm{~K}$.

Vertical lines indicate standard deviation 
compression. Interestingly, the absolute values of $\Delta U_{\text {in }}$ at strains $\varepsilon_{t} \leq 30 \%$ are equal for loadings of both types, although the deformation work (area under the $\sigma-\varepsilon$ curve) is appreciably larger in compression. The internal energy change is maximal in glass near the yield peak and is stored less rapidly at large strains in the plasticity region. At the elastic stage of total deformation $\left(\varepsilon_{t}<2 \%\right)$, the increase in $U_{\text {in }}$ is insignificant and agrees with the experimental data [34].

The $\Delta U_{\text {in }}$ versus $\varepsilon_{t}$ curve (Fig. 5, curve 1 ) is sigmoid, which is indicative of two stages of development of plasticity. With increasing strain, insignificant changes in $U_{\text {in }}$ in the elasticity region are followed by a rapid near-linear increase, which suggests an increase in the concentration of excited deformation structures in glass. However, at $\varepsilon_{t}>\varepsilon_{y}$, there is a definite tendency for the $\Delta U_{\text {in }}$ curves to plateau, i.e., for the process to become a steady-state plastic flow. Such behavior exactly agrees with the experimental data $[6 ; 34]$.

The data on the fraction of the stored energy $U_{\text {in }}$ in the total deformation work $W$, i. e., the ratio
$P=\Delta U_{\text {in }} / \Delta W$ within a chosen e range, suggest interesting conclusions on the plasticity mechanism in polymer glass. In stretching, $P=0.77$ at $\varepsilon_{t}=10 \%$ and then rap idly decreases to 0.57 at $\varepsilon_{t}=30 \%$. In compression, $P=0.97$ at $\varepsilon_{t}=10 \%$ and reduces to 0.74 at $\varepsilon_{t}=30 \%$. Thus, the fraction of the stored energy in the deformation work in stretching exceeds that in compression. The presented data show that, before the steadystate plastic flow stage, i. e., before $\varepsilon<30 \%$, the glassy poly methylene deformation work is mainly done to produce excited deformation defects, and this process is the main one in the polymer glass plasticity mechanism. This situation differs significantly from that observed in deformation of crystalline metals, where the work done is mostly converted to heat. The presented results demonstrate that the limiting stages in the kinetics of deformation of polymer glasses and crystalline metals are essentially different: in polymers, the limiting stage of plasticity is the nucleation of deformation defects, rather than their development (glide of dislocations in crystals).

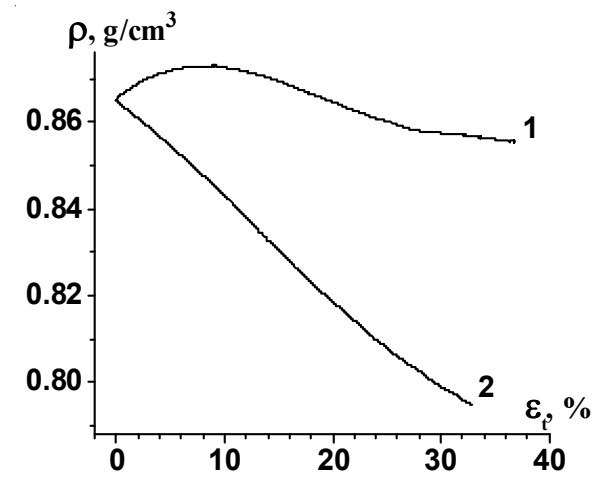

Fig. 4. Density-true strain curves in uniaxial (1) compression and (2) stretching, averaged over 32 specimens
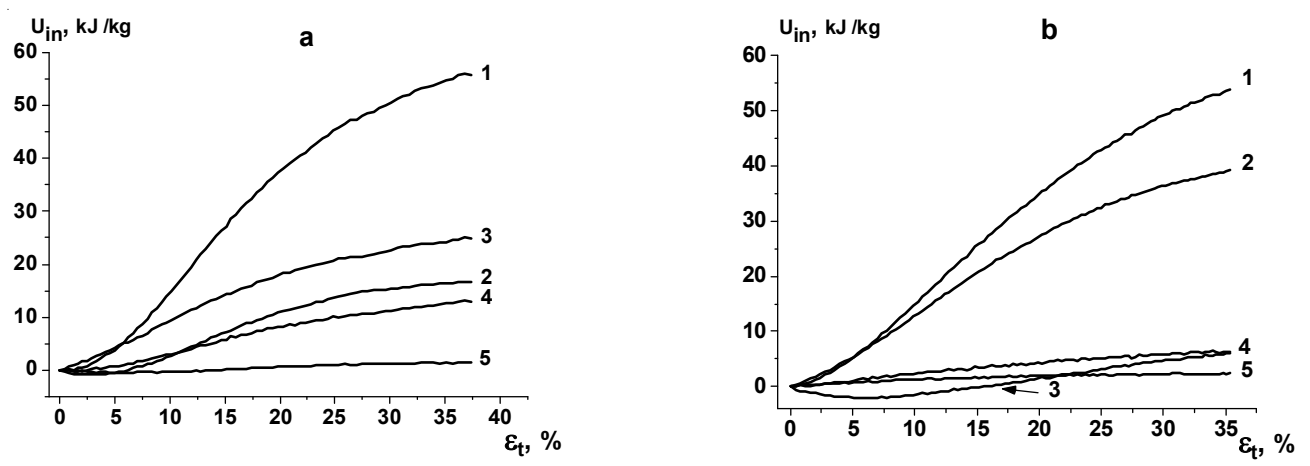

Fig. 5. Potential energy change and its components in uniaxial (a) compression and $(b)$ stretching at $50 \mathrm{~K}$ :

(1) the internal energy change $\Delta U_{\text {in }}$ and the contributions made to $\Delta U_{\text {in }}$ by (2) noncovalent interactions, (3) internal rotation angles, (4) bond angles, and (5) covalent bonds 
Let us now consider the contributions of interactions of various types to the storage of $U_{\text {in }}$. Fig. 3 demonstrates that the deformation of chemical bonds hardly contributes to the increase in $U_{\text {in }}$ (curves 5 ). The main contribution to $\Delta U_{\text {in }}$ in stretching is made by van der Waals noncovalent interactions (curves 2), more specifically, mainly their intermolecular components, as the calculations showed. The interactions of the other types (Fig. 5, $b$, curves 3-5) make no noticeable contribution to the total increase in $U_{\text {in }}$ of glass. This confirms the fact known for isotropic organic polymers that their mechanical behavior is primarily determined by the van der Waals interactions, whereas the intramolecular covalent interactions in deformation play no noticeable part.

The situation in compression is somewhat different. In this case, a marked contribution to the energy storage in deformation is made by changes in the energy of bond angles and internal rotation angles (Fig. 5, a, curves 3, 4). The contribution of the latter is even larger than the contribution of the noncovalent interactions. Unlike tensile deformation, where an increase in the free volume facilitates intramolecular relaxation and the internal energy change is mainly due to an increase in the interchain distance, the density in compression changes insignificantly. The high density in compression complicates intramolecular relaxation, which leads to an increase in the energy of the mildest interactions: the ones of rotation angles and bond angles. In other words, the similar energies $U_{\text {in }}$ of deformed PM in stretching and compression are differently redistributed in the material between various degrees of freedom: in stretching, the main contribution is made by the intermolecular interaction forces, and in compression, there is a noticeable contribution of changes in bond and rotation angles, which exceeds the contribution of the noncovalent interactions.

The simulation of the plastic deformation of the simplest real polymer, glassy PM, detected a number of features of this process. First of all, in the deformation in the polymer, an excess energy is stored, as in solids of other types, e.g. metallic crystals. The stored energy $U_{\text {in }}$ of PM glass initially increases to $\varepsilon \approx 30 \%$ and then plateaus to a limit. The observed limit corresponds to steady-state plastic flow of glass.
A large (75-95\%) fraction of the deformation work in PM glass is converted into the internal energy of glass, rather than dissipates to heat as in crystalline metals. This is indicative of difference in plasticity mechanism between the materials of both classes.

\subsection{Nonaffine Deformational Displace- ments}

Nowadays, it is commonly accepted $[4 ; 5$; $6 ; 21 ; 26 ; 48]$ that the main contribution to the plastic deformation of glass (both nonpolymer and polymer glasses) is provided by the nonaffine displacements of atoms arising during the formation of basic carriers of plasticity in glass, i.e. shear transformations. The construction and analysis of fields of atomic displacements for a number of glassy systems during their deformation or plastic flow were often used to visualize atomic processes occurring in materials under the action of external mechanical forces. However, in recent years, it became clear that the common field of atomic displacements is not an ideal instrument for studying deformations [21]. In [22], a new method was advanced to reveal local plastic rearrangements; it proved to be efficient in the analysis of plastic-deformation mechanisms in metallic glass $[6 ; 7 ; 22 ; 28 ; 45]$.

In the present paper, this approach was employed and fields of nonaffine displacements arising during deformation of glassy PM were analyzed. In order to calculate the magnitude of nonaffine displacements of carbon atoms (displacements of hydrogen atoms were not considered) relative to their nearest surrounding, mean-squared difference $\mathrm{D}^{2}(t, \mathrm{D} t)$ of real changes at distances between the considered particle and the atoms surrounding it and the distances that correspond to affine displacements $\varepsilon_{i j}$ in this range during time $\mathrm{D} t$ was calculated for each carbon atom during transition of the system from its state at time $t-\mathrm{D} t$ to its state at time $t$ :

$$
\begin{aligned}
& D^{2}(t, \Delta t)= \\
& =\sum_{n=1}^{N} \sum_{i=1}^{3}\left(r_{n}^{i}(t)-r_{0}^{i}(t)-\sum_{j=1}^{3}\left(\AA_{i j}-\mathrm{e}_{i j}\right)\left[r_{n}^{j}(t-\Delta t)-r_{0}^{j}(t-\Delta t)\right]\right)^{2} .
\end{aligned}
$$

Here, $r_{n}^{i}(t)$ is the $i$ th component of the radius vector of particle $n$ at time $t$, the zeroth index corresponds to the atom for which the calculation was performed, $\delta_{i j}$ is the Kronecker symbol, and $\varepsilon_{i j}$ is the strain tensor. In order to reduce the effect of thermal vibrations, in these calculations we used 
the coordinates not instantaneous but averaged over $1 \mathrm{ps}$. Adjusting the value of tensor $\varepsilon_{i j}$ that minimizes $D^{2}$ makes it possible to find such a local affine transformation that best reproduces the affine deformation of the environment of the considered particle. In order to estimate local structural rearrangements, we used $\bar{D}_{\text {min }}$, which characterizes the displacement of the considered atom relative to its local environment over time $\Delta t$ :

$$
\bar{D}_{\min }(t, \Delta t)=\sqrt{\min _{\varepsilon_{i j}}\left\{D^{2}(t, \Delta t)\right\} / N} .
$$

Note that, if instantaneous atomic coordinates are considered, their nonaffine displacements may be caused by not only rearrangements but also heat vibrations of atoms or their mobility in locally instable glassy structures. However, the effect of these factors on $\bar{D}_{\min }$ may be estimated through calculation of non affine atomic displacements for the undeformed samples. Characteristics of nonaffine displacements in systems $\mathrm{C} 1$ and $\mathrm{C} 2$ practically coincide. Therefore, the results averaged over both systems will be analyzed below.

Fig. $6, a$ shows normalized $\bar{D}_{\text {min }}$ distributions that were calculated for the region of low macroscopic strains of PM with an $\varepsilon=0.2 \%$ change as well as in the absence of macroscopic deformation during the same time interval as that taken for the abovementioned $0.2 \%$ strain. As seen from the figure, in the absence of deformation, the distribution has a maximum at $\bar{D}_{\min }=0.145 \mathrm{~A}^{\mathrm{n}}$ and goes to practically zero at $\bar{D}_{\text {min }}=0.7 \mathrm{~A}$, although some carbon atoms undergo larger displacements. On average, there are three atoms in a sample with $\bar{D}_{\text {min }}>1 \mathrm{~A}$. Deformation of a sample to $\varepsilon=5.2 \%$ leads to a certain broadening of the distribution toward large displacements and induces the appearance of relatively large nonaffine displacements to 2.6$2.8 \mathrm{E}$. An increase in the number of groups with $\bar{D}_{\min }>1 \mathrm{~A}$ is noticeable as well: $\sim 25$ groups per sample at strains from 0 to $0.2 \%$ and $\sim 57$ groups at strains from 5 to $5.2 \%$.

However, the character of the distribution is slight even at higher strains (Fig. 6, b). With an increase in e, the distribution broadens systematically and the number of groups with relatively large displacements increases (Fig. 7). Fig. 6 and 7 show that both the general form of distribution $D_{\min }$ and the number of groups with relatively large displacements continuously change with deformation. No qualitative changes are observed during the transition from low elastic deformations to high plastic deformations. The dependence of the number of relatively large displacements on deformation is close to linear, and the rate of their accumulation systematically drops with an increase in the number of displacements. It is interesting that the numbers of atomic displacements, $D_{\min }=1.0$ and $1.2 \mathrm{E}$, are weakly dependent on $\varepsilon$.

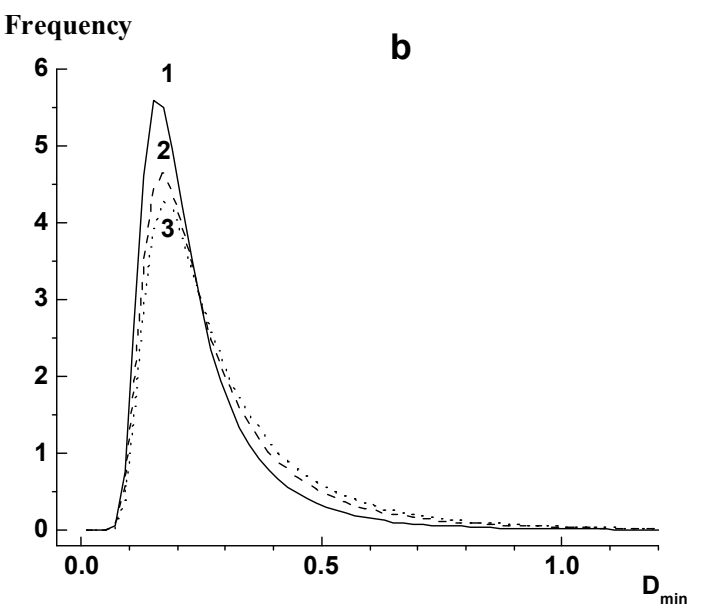

Fig. 6. Frequency curves of $D_{\min }$ distribution in the low strain region: $a$ - compression, and $b-$ stretching.

(a) heat fluctuations at $\varepsilon=(1) 0,(2) 0=>0.2$, and (3) $5.0=>5.2 \%$; (b) heat fluctuations in the region of modest and high strains at $\varepsilon=(1) 13.0=>13.2$, (2) $25.0=>25.2$, and (3) $29.0=>29.2 \%$. The step is $0.02 \mathrm{E}$ 


\section{ТЕХНИКО-ТЕХНОЛОГИЧЕСКИЕ ИННОВАЦИИ}

3.4. Changes in the Conformational Compositions of Chains During Their Deformation

Fig. 8 plots the frequency curve of the rotation angle distribution in chains of initial and deformed ( $\varepsilon=30 \%)$ PM samples. Transconformers and gauche conformers are clearly pronounced in the initial system, at angles of $\sim 120^{\circ}$ and $240^{\circ}$, intermediate states are practically absent. Uniaxialcompression deformation to $\varepsilon=30 \%$ entails only slight broadening of conformational peaks (Fig. 8, curve 2). The average conformational composition of PM chains in series $\mathrm{C} 1$ is practically the same; only the fraction of trans conformers insignificantly decreases from 61.4 to $60.9 \%$, mainly in the range of strains $\varepsilon=7-20 \%$. For series $\mathrm{C} 2$, the fraction of transconformers decreases from 60.4 to $59.9 \%$. A decrease in the strain rate by an order of magnitude has no effect on the ratio of trans and gauche conformers in a sample. This result shows that the conformational composition of glassy PM chains remains almost undisturbed by plastic deformation, although at $\varepsilon=30 \%$, the macroscopic plastic yield is well-developed. The residual strain of such a polymer after its complete unloading attains $\varepsilon_{\text {res }} \sim 15 \%$. A similar behavior of glassy polymers (PP and PC) was observed in [17; 31].

All these data conflict with the mechanism of low temperature plasticity of polymer glass caused by changes in the conformational composition of the chains (the model of forced rubber-like elasticity [22]). It is quite probable that, for glassy polymers, the deformation mechanism changes at $T_{\text {def }}$ values close to the $T_{g}$ values and is controlled by conformational rearrangements in chains. At relatively high $T_{\text {def }}$ values, conformational

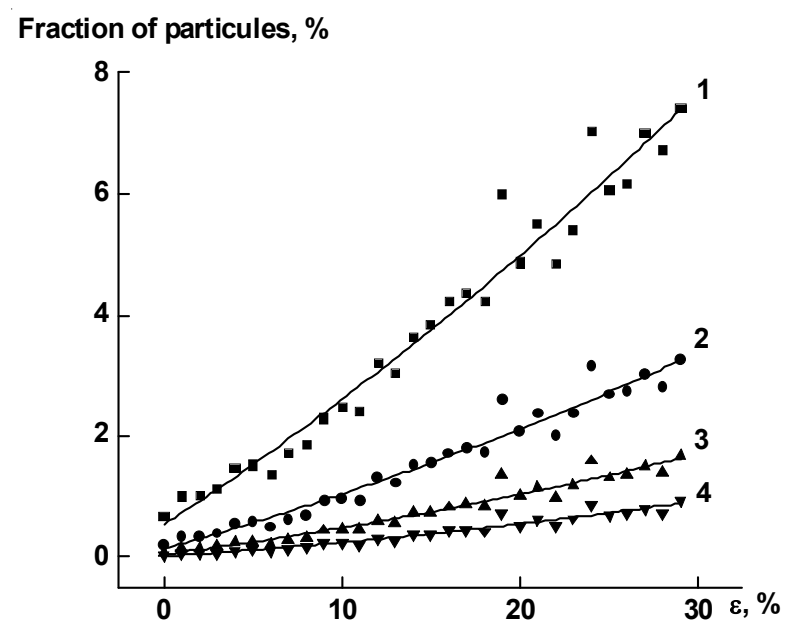

Fig. 7. Fractions of carbon atoms with $\bar{D}_{\text {min }}$ values exceeding (1) 0.6, (2) 0.8, (3) 1.0, and (4) 1.2 E versus strain. Continuous curves refer to the mean-squared approximation

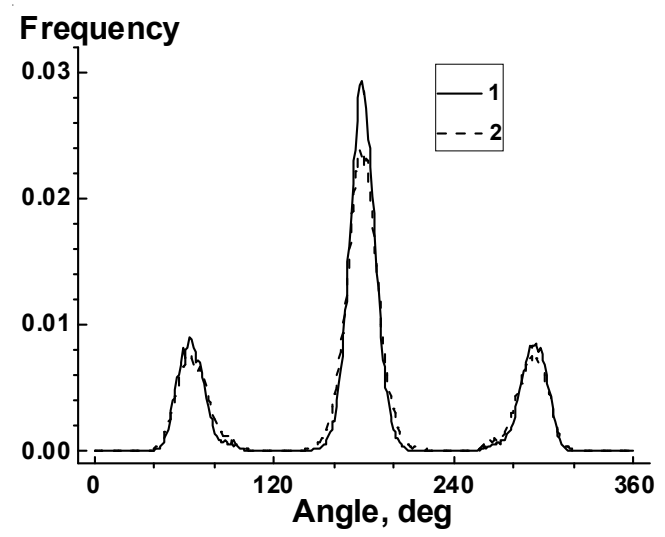

Fig. 8. Frequency curves of rotation angle distributions for the initial configuration and the configuration deformed by $30 \%$. The step is $1^{\circ}$ 
rearrangements in glassy polymers become possible $[2 ; 6 ; 34]$. In any case, the Robertson conformational plasticity model [41] agrees well with experimental results at $T_{\text {def }}$ values close to the $T_{g}$ values $[6 ; 19]$. Nevertheless, the literature data on the computeraided simulation of plasticity of glassy polymers $[17 ; 26 ; 33]$, as well as the results of the present paper, indicate that the observed small changes in the conformational composition of chains at a marked level of plastic deformation of such systems are hardly responsible for their plasticity.

\subsection{Nonaffine Displacements and Conformational Rearrangements}

Transgauche transitions should cause noticeable nonaffine displacements of atoms involved in conformational rearrangements. This important issue for gaining insight into the mechanism of plastic deformation of polymers requires quantitative estimates. To solve this problem, the fraction of units that were simultaneously involved in conformational rearrangements was calculated for all polymer units with non affine displacements exceeding a certain level of $D_{\text {min, off }}$ for a $0.2 \%$ strain increment (Fig. 9).

There are three strain regions: low strains $(0 \%<\varepsilon<5 \%)$, the region near the yield peak $(7 \%<\varepsilon<13 \%)$, and the region of welldeveloped plastic yield $(25 \%<\varepsilon<30 \%)$. The fraction of units participating in transgauche transitions increases with an increase in $D_{\min \text {, off }}$ However, among all atoms with relatively high values of $\bar{D}_{\text {min }}$, the fraction of atoms directly involved in conformational transitions (even for the largest displacements, with $\bar{D}_{\text {min }}>2.5 \mathrm{E}$ ) is small: $\sim 8 \%$ in the elasticity region and $\sim 25 \%$ in the region of developed plastic flow.

Such a low contribution of groups of atoms participating in conformational rearrangements may be explained by the fact that the conformational transition entails a local rearrangement affecting a relatively large number of neighboring atoms. To verify this statement, displacements in chain fragments consisting of at least 10 units and having $\bar{D}_{\min }>D_{\min \text {, off were }}$ considered. The table lists the percentages of those fragments in which at least one unit is involved in conformational rearrangement at various levels of deformation. It is seen that, even in the region of developed plastic yield, $\sim 2 / 3$ of the most mobile fragments $\left(\bar{D}_{\min }>2.5 \mathrm{E}\right)$ are not involved in transgauche rearrangements.

Fig. 10 presents the spatial distribution of units in PM chains with nonaffine displacements $\bar{D}_{\min }>0.6 \mathrm{E}$ in one of the samples at the onset of deformation in the region of yield tooth and during plastic flow. (The projections are chosen so that, in each case, the spatial distribution of

\section{Fraction of conformational rearrangements}

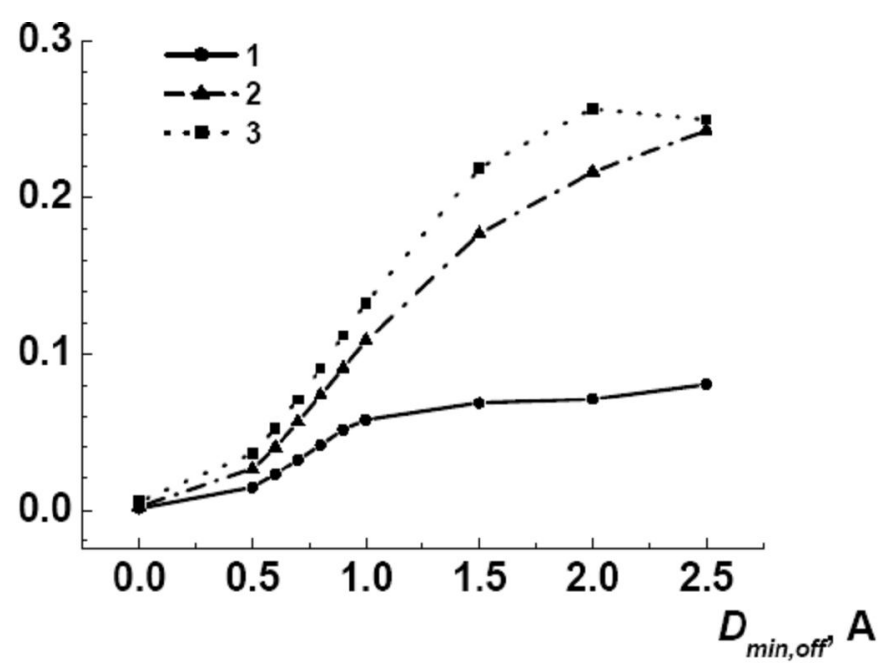

Fig. 9. The fraction of carbon atoms involved in conformational transitions among all PM atoms for which $\bar{D}_{\text {min }}>D_{\min , \text { off }}$ The fractions are presented for three strain regions $\varepsilon$ :

(1) the elasticity region, $0 \%<\varepsilon<5 \%$; (2) close to the yield drop, $7 \%<\varepsilon<13 \%$; and (3) during developed plastic yield, $25 \%<\varepsilon<30 \%$ 


\section{ТЕХНИКО-ТЕХНОЛОГИЧЕСКИЕ ИННОВАЦИИ}

units is seen better.) An increase in the number of units with these displacements and their noticeable clustering with an increase in strain e are well seen, as confirmed by analysis of such distributions for different samples.

The above picture allows some important conclusions to be made about the character of the low-temperature plastic deformation of glassy $\mathrm{PM}$ in the uniaxial-compression regime. It is seen that nonaffine (plastic) displacements arise very early at a level of $\varepsilon \sim 1 \%$ (or even earlier), that is, when only linear Hookean deformations are assumed to occur in glass and plastic rearrangements are still absent. This result demonstrates that deformation in disordered solids cannot be considered purely elastic and uniform from the very early stages of loading. Such behavior of glass was described in [6].

The number of sites at which nonaffine atomic displacements occur is small at low $\varepsilon$ (Table 2). Obviously, they appear independently at different sites of a sample. However, with an

a
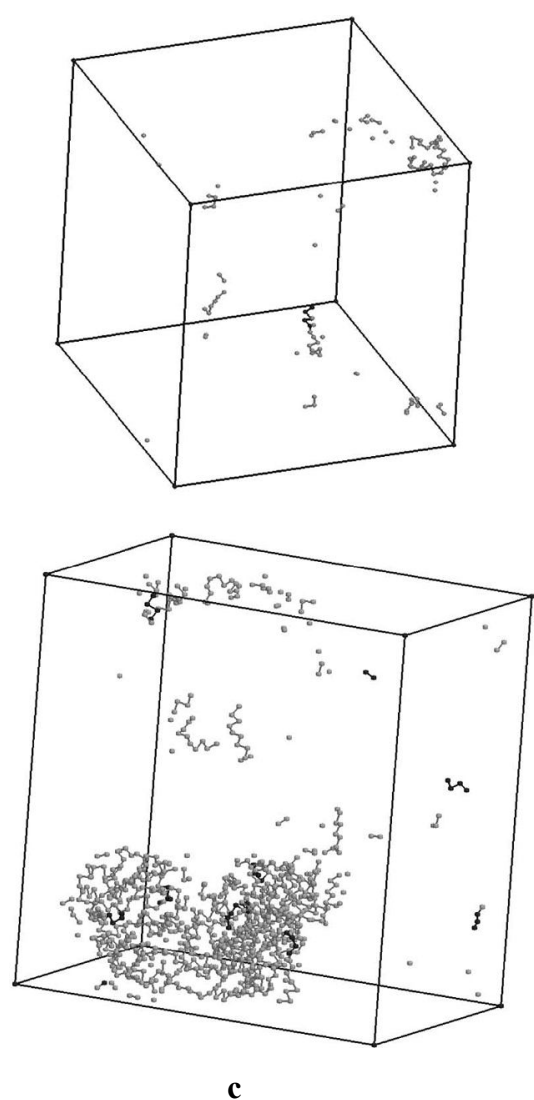

increase in $\varepsilon$, the number of non affine atomic displacements grows and a certain spatial clustering of plastic events in the glass occurs. The latter circumstance may imply that, as the concentration of shear transformations increases with an increase in $\varepsilon$, they do not behave independently and new shear transformations are easier nucleated in those regions of the glass where plastic deformations have already happened [24]. In Fig. 10, atomic displacements related to local changes of conformations in chains are shown as well (marked with black). The fraction of conformational rearrangements in the system remains insignificant. This fact means that the conformational rearrangements in chains during plastic deformations of glassy polymers are governed by only one of the local mechanisms that are responsible for atomic displacements related to low-temperature deformation.

In order to clear up whether there is a correlation between large atomic displacements,

b

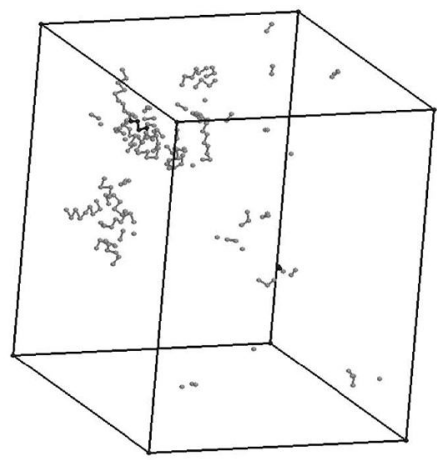

Fig. 10. Distribution of nonaffine displacements $\bar{D}_{\min }>0.6 \mathrm{E}$ of chain units in one of the samples at strains (a) $1 \%<\varepsilon<1.2 \%$, (b) $10 \%<\varepsilon<10.2 \%$, and (c) $20 \%<\varepsilon<20.2 \%$. Units in which conformational rearrangements occurred are indicated with black 
the corresponding correlation functions along chains, $C F_{\text {intra }}(\Delta N)$, were calculated:

$$
\begin{aligned}
& C F_{\text {intra }}(\Delta N)= \\
& =\frac{\frac{1}{N_{c h}-\Delta N} \sum_{i=1}^{N_{c h}-\Delta N}\left(\bar{D}_{\text {min, } i}-\left\langle\bar{D}_{\text {min }, i}\right\rangle\right)\left(\bar{D}_{\text {min }, i+\Delta N}-\left\langle\bar{D}_{\text {min }, i+\Delta N}\right\rangle\right)}{\frac{1}{N_{c h}} \sum_{i=1}^{N_{c h}}\left(\bar{D}_{\text {min, }, i}-\left\langle\bar{D}_{\text {min, }, i}\right\rangle\right)^{2}}
\end{aligned}
$$

where $i$ is the number of particles along the chain, $N_{\mathrm{ch}}$ is the chain length, $\bar{D}_{\min , i}$ is the value of $\bar{D}_{\text {min }}$ for the $i$ th particle, and $\left\langle\bar{D}_{\text {min, } i}\right\rangle$ is the system-averaged displacement of the $i$ th particle from the chain end.

In addition, intermolecular correlations $C F_{\text {inter }}(R)$ were calculated:

$$
\begin{aligned}
& C F_{\text {inter }}(R)= \\
& =\frac{\frac{1}{N-N_{\text {null }}} \sum_{i=1}^{N-N_{\text {mul }}}\left(\bar{D}_{\text {min, }, i}-\left\langle\bar{D}_{\text {min }}\right\rangle\right)\left(\bar{D}_{\text {min }, i+\Delta r}-\left\langle\bar{D}_{\text {min }}\right\rangle\right)}{\frac{1}{N} \sum_{i=1}^{N}\left(\bar{D}_{\text {min }, i}-\left\langle\bar{D}_{\text {min }}\right\rangle\right)^{2}} .
\end{aligned}
$$

Here, $R$ is the distance from a particle to the center of spherical layer $\Delta r$ around it, where the layer width is $1 \mathrm{E} ; N$ is the number of particles in the system; $N_{\text {null }}$ is the number of particles for which other particles are absent within layer $\Delta r ; \bar{D}_{\min , i}$ is the value of $\bar{D}_{\min }$ for the $i$ th particle; is the system-averaged $\bar{D}_{\text {min }}$ value; and $\bar{D}_{\text {min, }, i \Delta r}$ is the value of $\bar{D}_{\text {min }}$ averaged over particles in layer $\Delta r$ with respect to the $i$ th particle.

In the calculation of $C F_{\text {inter }}$, the 20 nearest neighbors of the $i$ th particle along the chain were not taken into account.

Correlation functions are presented in Fig. 11. The correlations function along the chain decays exponentially (the continuous curve in Fig. 9, $a$ ) with an $e$ fold drop approximately at the eighth unit at low strains and at the tenth unit in the plastic-deformation region. This circumstance implies that displacements affect chain segments consisting of 16-20 monomers at most and that the sizes of these segments are weakly affected by the value of strain. Because fragments of transconformers consisting of 16-20 units and, hence, having lengths of 26-30 E are very seldom, the intramolecular correlation of nonaffine displacements covers the spatial region of $\sim 20 \mathrm{E}$ at most.

The correlation function for interchain displacements has a somewhat more complex view, a circumstance that is probably related to the correlated motion of fragments of neighboring chains. If, in this case, the distance at which the correlation drops by a factor of $e$ is taken also as a characteristic distance, this value will be $6.0 \mathrm{E}$ at $0-0.2 \%$ and $8.6 \mathrm{E}$ at $29-29.2 \%$ strain. These data correspond to sizes of $12-19 \mathrm{E}$; that is the magnitudes of intra and intermolecular correlations are comparable. An analysis of displacements of individual chain fragments did not reveal any dominant mechanism of displacements.

Thus, the displacements of short (4-6 units) chain fragments are absent. Plastic displacements are always produced via correlated motions of chain sections consisting of at least ten units. This fact indicates the absence of plastic masstransfer mechanisms in chains via systematically repeating rearrangements of short chain segments, e.g. short conformational sequences, strophons ("rotons"), dislocations, or disclinations [34]. These statements agree well with findings from $[20 ; 21 ; 44]$.

In $[1 ; 5 ; 20 ; 26]$, atomic-level deformations in PP and PC chains were analyzed. It was found that during the low-temperature deformations of

Table 2

Percentages of relatively long chain fragments (at least ten $-\mathrm{CH}_{2}-$ units) in which the trans-to-gauche transition was observed

\begin{tabular}{|c||c|c|c||}
\hline & $0-5 \%$ & $7-13 \%$ & $25-30 \%$ \\
\hline \hline $0.6 \mathrm{E}$ & $7.5 \%$ & $15.1 \%$ & $21.6 \%$ \\
\hline \hline $0.8 \mathrm{E}$ & $7.0 \%$ & $19.2 \%$ & $27.6 \%$ \\
\hline \hline $1 \mathrm{E}$ & $7.2 \%$ & $24.7 \%$ & $32.6 \%$ \\
\hline \hline $1.2 \mathrm{E}$ & - & $25.9 \%$ & $35.8 \%$ \\
\hline
\end{tabular}


the indicated types of polymer glass, even longer chain fragments are involved in plastic yield. These results were obtained via the methods of potentialenergy minimization at $0 \mathrm{~K}$. In our opinion, the plastic deformation of glassy PM involves shorter chain fragments than those in the above papers because, in our case, the value of $T_{\text {def }}$ is higher.

\section{Conclusions}

Simulation of the low-temperature deformation of the all-atom PM model has been performed for the first time. With the use of the polymerization method within the framework of molecular dynamics simulation, samples of the low-temperature amorphous PM with various molecular-mass distributions are prepared. Numerical experiments on the uniaxial lowtemperature compression made it possible to perform a thorough analysis of local atomic displacements of $-\mathrm{CH}_{2}-$ groups of chains during deformation.

In the low-strain region at $\varepsilon_{\text {def }} \leq 5 \%$, local structural rearrangements containing up to 16-20 $-\mathrm{CH}_{2}-$ units arise in polymer chains. Thus, in a glassy sample, a uniform lattice expansion in the region of low strains (which are usually considered to be Hookean strains) is accompanied by the same local displacements of chain fragments as those observed in the region of delayed elasticity and plasticity.

The analysis of nonaffine displacements of polymer units at yield tooth $\left(\varepsilon_{\text {def }}=10-13 \%\right)$ and in the region of stationary plastic flow $\left(\varepsilon_{\text {def }}>\right.$
$15 \%$ ) showed that, similarly to the united-atom model of PM $[8 ; 10]$, no substantial changes in the deformational behavior of chains occur relative to that in the low strain region. However, the total number of units with relatively large nonaffine displacements increases at high strains and their amplitude grows as well.

With an increase in deformation, the number of conformational rearrangements increases. However, the conformational composition of chains changes insignificantly, only by $0.6 \%$, mainly in the strain range from 5 to $20 \%$. During deformation, a noticeable intramolecular correlation of displacements of particles is observed. Moreover, in most cases, the rearrangements are localized and segments with an average length of no more than 16-20 units are affected. They are comparable in the all-atomic model, unlike those in the united-atom model, where the intermolecular correlation was appreciably lower than the intramolecular correlation.

While nonaffine displacements of long parts of the chain in the united-atom model are mainly related to the "sliding" of chains with respect to each other [8], practically no sliding is observed in the full-atomic model. This is one main difference between the more detailed model and the united-atom model of PM.

Our calculations showed that, although transgauche transitions contribute to structural rearrangements during the deformation of PM, they play an indecisive role even in the region of developed plastic yield at $30 \%$ compression deformation, where the corresponding atomic
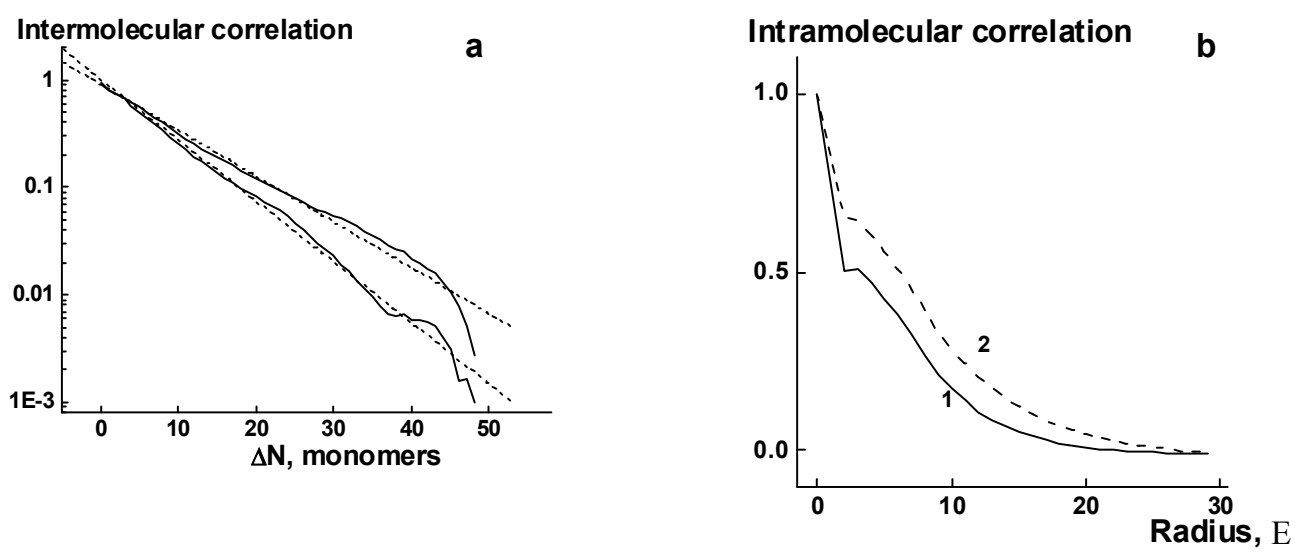

Fig. 11. The correlation function of nonaffine displacements along the chain in semilogarithmic coordinates, where dashed lines represent $(a)$ the mean-squared approximation of the exponential function and $(b)$ their intermolecular correlation for $\mathrm{e}=(1)$ 0-0.2 \% and (2) $29.0-29.2 \%$ 
displacements are responsible for $\sim 30 \%$ of the total number of atomic displacements in chains arising during plastic deformation.

\section{Acknowledgments}

This work was supported by the Division of Chemistry and Materials Sciences of the Russian Academy of Sciences, within the framework of Program of Basic Research no. 2. Computational resources were provided by the Joint Supercomputer Center, Russian Academy of Sciences.

\section{REFERENCES}

1. Allen M.P., Tildesley D.J. Computer Simulation of Liquids. Clarendon, Oxford, 1987.520 p.

2. Argon A.S. Plastic Deformation in Metallic Glasses. Acta. Metall., 1979, no. 27, p. 47.

3. Argon A.S. A Theory for the LowTemperature Plastic Deformation of Glassy Polymers. Philos. Mag., 1973, no. 28, p. 939.

4. Argon A.S., Demkowicz M.J. Atomistic Modelling of Plastic Deformation of Glassy Polymers. Philos. Mag., 2006, no. 86, p. 4153.

5. Argon A.S., Mott P.H., Suter U.W. Simulation of Plastic Deformations in a Flexible Chain Glassy Polymer. Phys. Status Solidi B, 1992, no. 172, p. 193.

6. Argon A.S. The Physics of Deformation and Fracture of Polymers. New York, Cambridge University Press, 2013.235 p.

7. Bailey N., Schiotz J., Jacobsen K. Atomistic Simulation Study of the Shear Band Deformation Mechanism in Mg" Cu Metallic Glasses. Phys. Rev. B: Condens. Matter., 2006, no. 73, p. 064108.

8. Balabaev N.K., Mazo M.A., Lyulin A.V., Oleinik E.F. Plastic Deformation of Glassy PM: Computer Aided Molecular Dynamic Simulation. Polym. Sci., Ser. A, 2010, no. 52, p. 633.

9. Baron A.A, Bakhracheva Yu.S. The Method for Lifetime Estimation Through the Mechanical Properties in Tension. Mechanika (Kaunas), 2004, no. 3, pp. 29-32.

10. Barrat J.L., Baschnagel J., Lyulin A., Molecular Dynamics Simulations of Glassy Polymers. Soft Matter., 2010, no. 6, p. 3430.

11. Berendsen H.J.C., Postma J.P.M., Gunsteren W.F., Di Nola A., Haak J.R. Molecular Dynamics With Coupling to an External Bath. J. Chem. Phys., 1984, no. 81, p. 3684.

12. Berthier L. Dynamic Heterogeneity in Amorphous Materials. Physics, 2011, no. 4, p. 42.

13. Bouchbinder E., Langer J.C., Procaccia I. A Thermal Shear-Transformation-Zone Theory of
Amorphous Plastic Deformation. II. Analysis of Simulated Amorphous Silicon. Phys. Rev. E., 2007, no. 75 , p. 036108.

14. Bulatov V., Argon A.A. A Stochastic Model for Continuum Elasto-Plastic Behavior. II. A Study of the Glass Transition and Structural Relaxation. Model. Simul. Mater. Sci. Eng., 1994, no. 2, p. 185.

15. Bulatov V., Argon A.A. A Stochastic Model for Continuum Elasto-Plastic Behavior: III. Plasticity in Ordered Versus Disordered Solids. Model. Simul. Mater. Sci. Eng., 1994, no. 2, p. 203.

16. Bulatov V., Argon A.A. A Stochastic Model for Continuum Elasto-Plastic Behavior. I. Numerical Approach and Strain Localization. Model. Simul. Mater. Sci. Eng., 1994, no. 2, p. 167.

17. Capaldi F.M., Boyce M C., Rutledge G.C. Molecular Response of a Glassy Polymer to Active Deformation. Polymer, 2004, no. 45, p. 1391.

18. Cheng Y.Q., Cao A.J., Sheng H.W., Ma E. Local Order Influences Initiation of Plastic Flow in Metallic Glass: Effects of Alloy Composition and Sample Cooling History. Acta Mater., 2008, no. 56, p. 5263.

19. Crist B. A Comprehensive Treatment. Cahn R., Haasen P., Kramer E.J., eds. Material Science Technology. VCH, Wein heim, 1995, vol. 12, p. 797.

20. Dasgupta R., George H., Hentschel E., Procaccia I. Yield Strain in Shear Banding Amorphous Solids. Phys. Rev., 2013, vol. E 87, p. 022810.

21. Falk M.L, Maloney C.E. Simulating the Mechanical Response of Amorphous Solids Using Atomistic Methods. Eur. Phys. J., 2010, vol. B 75, p. 405.

22. Falk M.L., Langer J.S. Dynamics of Viscoplastic Deformation in Amorphous Solids. Phys. Rev. E., 1998, no. 57, p. 7192.

23. Gendelman O.V., Manevich L.I. Structural Defects and Soft Localized Modes in Disordered Systems. JETP, 1996, vol. 83, no. 1, p. 155.

24. Hossain D., Tschopp M.A., Ward D.K., Bouvard J.L., Wang P., Horstemeyer M.F. Heterogeneous Dynamics During Deformation of a Polymer Glass. Polymer, 2010, no. 51, p. 6071.

25. Hoy R.S. Why is Understanding Glassy Polymer Mechanics So Difficult? J. Polym. Sci. B, 2011, no. 49 , p. 979.

26. Hutnik M., Argon A.S., Suter U.W. Simulation of Elastic and Plastic Response in the Glassy Polycarbonate of 4,4'-Isopropylidenediphenol. Macromolecules, 1993, no. 26, p. 1097.

27. Kargin V.A. Selected Works. The Problems of Polymer Science. Moscow, Nauka Publ., 1986.

28. Lee S., Rutledge G.C. Plastic Deformation of Semicrystalline Polyethylene by Molecular Simulation. Macromolecules, 2011, no. 44, p. 3096.

29.Lemak A.S., Balabaev N.K. A Comparison Between Collisional Dynamics and Brownian Dynamics. Mol. Simul., 1995, no. 15, p. 223. 
30. Luise R.R., Yannas I.V. Introduction to Molecular Dynamics Simulation. Biserano J., Dekker M., eds. Computation Modeling of Polymers. New York, 1992, pp. 1-28.

31. Lyulin A.V., Balabaev N.K., Mazo M.A., Michels M.A. Molecular Dynamics Simulation of Uniaxial Deformation of Glassy Amorphous Atactic Polystyrene. Macromolecules, 2004, no. 37, p. 8785.

32. Lyulin A.V., Vorselaars B., Mazo M.A., Balabaev N.K., Michels M.A. Strain Softening and Hardening of Amorphous Polymers: Atomistic Simulation of Bulk Mechanics and Local Dynamics. Europhys. Lett., 2005, no. 71, p. 618.

33. Mahajan D.K., Estevez R., Basu S. Ageing and Rejuvenation in Glassy Amorphous Polymers. J. Mech. Phys. Sol., 2010, no. 58, p. 1474.

34. Oleinik E.F., Rudnev S.N., Salamatina O.B., Kotelyanskiy M.I. Mechanisms of an Elastic Deformation in Solid Polymers: Solid-Like and LiquidLike Processes. Polym. Sci., Ser. A, 2008, no. 50, p. 494.

35. Pacheco A.A., Batra R.C. Analysis of Structural Changes During Plastic Deformations of Amorphous Polyethylene. Polymer, 2013, no. 54, p. 819.

36. Paitner P., Coleman M., Koenig J. Vibrational Spectroscopy and Its Application to Polymeric Materials. Wiley, New York, 1982.

37. Pakhomov P.M., Korsukov V.E., Shablygin M.V., Novak I.I. Correlation Between Mechanical Properties and Conformation of the Polymer Composition. Polymer Science, Ser. A, 1984, no. 26, p. 1288.

38. Papakonstantopoulos G.J., Riggleman R.A., Barrat J.L., De Pablo J.J. Calculation of Local Mechanical Properties of Filled Polymers. Phys. Rev. E, 2008, no. 77, p. 041502.

39. Perez J. Physics and Mechanics of Amorphous Polymers. Balkema, Rotterdam, 1998.

40. Riggleman R.A., Lee H.N., Ediger M.D., De

Pablo J.J. Heterogeneous Dynamics During Deformation of a Polymer Glass. Soft Matter., 2010, no. 6 , p. 287.

41. Robertson R.E. Theory for the Plasticity of Glassy Polymers. J. Chem. Phys., 1966, no. 44, p. 3950.
42. Rodney D., Tangu A., Vandembroucq D. Modeling the Mechanics of Amorphous Solids at Different Length Scale and Time Scale. Model. Simul. Mater. Sci. Eng., 2011, no. 19, p. 083001.

43. Rottler J. Fracture in Glassy Polymers: a Molecular Modeling Perspective. J. Phys.: Condens. Matter, 2009, no. 21, p. 463101.

44. Shapochkin V.I., Semenova L.M., Bakhracheva Yu.S., Gyulikhandanov E.L., Semenov S.V. Effect of Nitrogen Content on the Structure and Properties of Nitrocarburized Steel. Metal Science and Heat Treatment, 2011, vol. 52, no. 9-10, pp. 413-419.

45. Shi Y., Falk M. Atomic Scale Simulations of strain Localization in Three-Dimensional Model of Amorphous Solids Phys. Rev. B: Condens. Matter., 2006, no. 73, p. 214201.

46. Siesler H., Rheo-Optical Fourier-Transform Infrared Spectroscopy: Vibrational Spectra and Mechanical Properties of Polymers. Adv. Polym. Sci., 1984 , no. 65 , p. 1.

47. Strelnikov I.A., Balabaev N.K., Mazo M.A., Oleinik E.F. Analysis of Local Rearrangements in Chains During Simulation of the Plastic Deformation of Glassy PM. Polymer Science, Ser. A, 2014, vol. 56, no. 2, p. 219.

48. Theodorou D.N., Suter U.W. Local Structure and the Mechanism of Response to Elastic Deformation in a Glassy Polymer. Macromolecules, 1986, no. 19, p. 379.

49. Utz M., Atallah A.S., Robyr P., Widmann A.H., Ernst R.R., Suter U.W. Solid-State NMR Investigation of the Structural Consequences of Plastic Deformation in Polycarbonate. 1. Global Orientational Order. Macromolecules, 1999, no. 32, p. 6191.

50. Vorselaars B., Lyulin A.V., Michels M.A. Deforming Glassy Polystyrene: Influence of Pressure, Thermal History, and Deformation Mode on Yielding and Hardening. J. Chem. Phys., 2009, no. 130, p. 074905.

51. Weiner S.J., Kollman P.A., Case D.A., Singh U.C., Ghio C., Alagona G. A New Force Field for Molecular Mechanical Simulation of Nucleic Acids and Proteins. J. Am. Chem. Soc., 1984, no. 106, p. 765.

\section{МОЛЕКУЛЯРНО-ДИНАМИЧЕСКОЕ МОДЕЛИРОВАНИЕ НИЗКОТЕМПЕРАТУРНОЙ ДЕФОРМАЦИИ АТОМОВ СТЕКЛООБРАЗНОГО ПОЛИМЕТИЛЕНА}

\section{Мазо Михаил Абрамович}

Кандидат физико-математических наук, старший научный сотрудник,

Институт химической физики им. Н. Н. Семенова РАН

mikhail.mazo1@gmail.com

ул. Косыгина, 4, 119991 г. Москва, Российская Федерация 


\section{Стрельников Иван Александрович}

Кандидат физико-математических наук, научный сотрудник, Институт химической физики им. Н. Н. Семенова РАН strlnkv@gmail.com ул. Дмитрия Ульянова, 5, 119333 г. Москва, Российская Федерация

\section{Балабаев Николай Кириллович}

Кандидат физико-математических наук, зав. лабораторией, Институт математических проблем биологии РАН balabaev@psn.ru ул. Институтская, 4, 142290 г. Пущино, Российская Федерация

\section{Гусарова Елена Александровна}

Научный сотрудник,

Институт химической физики им. Н. Н. Семенова РАН

elena.gusarova.53@mail.ru

ул. Косыгина, 4, 119991 г. Москва, Российская Федерация

\section{Олейник Эдуард Федорович}

Доктор химических наук, главный научный сотрудник, Институт химической физики им. Н. Н. Семенова РАН efoleinik@gmail.com ул. Косыгина, 4, 119991 г. Москва, Российская Федерация

\section{Берлин Александр Александрович}

Доктор химических наук, профессор, академик Российской академии наук, директор Института химической физики им. Н. Н. Семенова РАН berlin@chph.ras.ru ул. Косыгина, 4, 119991 г. Москва, Российская Федерация

Аннотация. Молекулярно-динамическое моделирование пластического течения стеклообразного полиметилена осуществляется при деформациях до $\varepsilon=30 \%$ в случае одноосного сжатия и $\varepsilon=60 \%$ в случае растяжения при температуре $50 \mathrm{~K}$. Bсе атомы цепей стеклообразного полиметилена представлены в явном виде. Расчеты проводились для двух серий образцов с различным молекулярно-массовым распределением цепей. Анализ показал, что число перестроек цепей при деформации мала и такие перестановки не играют решающую роль в рассматриваемом диапазоне пластичности стеклообразного полиметилена, даже в случае деформации $\varepsilon>15 \%$, на стадии развитого пластического течения.

Ключевые слова: полиметилен, потенциальная энергия, пластическое деформирование, молекулярная масса, фрагменты цепей, низкие штаммы. 